\title{
Women's Motives for Not Participating in Preconception Counseling: Qualitative Study
}

\author{
E.J. Hoslia $\quad$ J.Elsinga ${ }^{b} \quad$ S.E. Buitendijk ${ }^{a} \quad$ W.J.J. Assendelft ${ }^{b}$ \\ K.M. van der Pal-de Bruin ${ }^{\text {a }}$ \\ a Department of Prevention and Health, TNO Quality of Life, and ${ }^{\mathrm{b}}$ Department of Public Health and \\ Primary Care, Leiden University Medical Center, Leiden, The Netherlands
}

\section{Key Words}

Preconception counseling $\cdot$ General practice $\cdot$ Pregnancy $\cdot$ Nonresponse $\cdot$ Interview study

\begin{abstract}
Aims: Information about risk factors and preventive measures given before conception is estimated to prevent 15 $35 \%$ of adverse pregnancy outcomes. We aimed to identify women's motives for not responding to an invitation for preconception counseling (PCC) from their general practitioner. Methods: A purposive sample of 11 women who did not respond to an invitation for PCC and who became pregnant within 1 year was interviewed. Results: Three key themes influencing nonresponse emerged from the data: perceived knowledge, perceived lack of risk and a misunderstanding of the aim of PCC. Conclusion: For successful future implementation of PCC, a more tailored approach may be necessary for certain (groups of) women, addressing the reasons why women do not consider themselves part of the target group for PCC.

Copyright $\odot 2008$ S. Karger AG, Basel
\end{abstract}

\section{Introduction}

In the Netherlands, at least $20 \%$ of all known pregnancies end in an adverse outcome, such as miscarriage, preterm birth, low birth weight, perinatal death and congenital malformations $[1,2]$. Information about risk factors and preventive measures given timely, that is before con- ception, is estimated to prevent $15-35 \%$ of these adverse pregnancy outcomes [2-9]. Preconception counseling (PCC) addresses risk factors that are present prior to pregnancy. By either eliminating or altering risk factors during this period, pregnancy outcome may improve [8]. PCC encompasses information about lifestyle, obstetrical and gynecologic history, diseases in the (future) mother, family history for (congenital) hereditary diseases, and medication use. The concept of PCC is relatively simple and promising, but to be successful it is crucial to make PCC available to all prospective parents. Routine implementation and evaluation of PCC in primary care was the aim of the Dutch research project 'Parents to be'. 'Parents to be' is the first project wherein PCC has been offered routinely in a presumed low-risk population. In this project, PCC has been introduced among 30 general practitioners, working in 11 cooperation units of general practices in the western part of the Netherlands [10]. The actual response lagged behind the expected response, however. On average, $55 \%$ of the women who received an invitational letter did not respond at all. Furthermore, analysis of the data showed that about a quarter of the pregnancies that occurred within 1 year after an invitation was in the group of nonresponders. For successful future implementation of PCC in the population of all prospective parents, it is important to have insight into the motives of women who are not interested in PCC. Because little is known about this topic, we explored the motives of women who did not respond to the PCC invitation in the 'Parents to be' project and who became pregnant within 1 year after the invitation, in a qualitative, interview-based study.

\section{KARGER \\ Fax +4161306 1234 \\ E-Mail karger@karger.ch}

www.karger.com
(C) 2008 S. Karger AG, Basel

$1422-2795 / 08 / 0113-0166 \$ 24.50 / 0$

Accessible online at:

www.karger.com/cmg
Esther J. Hosli, $\mathrm{PhD}$

TNO Quality of Life, Department of Prevention and Health

PO Box 2215

NL-2301 CE Leiden (The Netherlands)

Tel. +31 71518 1822, Fax +31 71518 1920, E-Mail esther.hosli@tno.nl 


\section{Methods}

\section{Participants}

In the 'Parents to be' project, 30 general practitioners actively offered PCC to all women aged 18-40 over a 3 -year period. General practitioners reviewed lists of these women and excluded women with adverse social circumstances. The remaining women received an invitation for PCC. They were requested to indicate whether they were interested in PCC, and if so, when they were contemplating pregnancy. Those who were both interested and contemplating pregnancy within 1 year were invited for PCC. All pregnancies occurring within 1 year of an invitation were monitored [10].

In the year 2001, 128 women who did not respond to the invitation for PCC got pregnant within 1 year after they had received the invitation. We selected women from this group for interviews on the basis of characteristics we expected to be of influence on motives for nonresponse, namely previous pregnancy before invitation, age and education (table 1). Information about these characteristics was retrieved from questionnaires the women filled in and from their medical files, but was not available for all women. Some characteristics of the general practices (solo, duo or group practice; city or village) were also taken into account. We did not strive to fill all the cells in the table, but strove for a representation of the individual characteristics in the resulting sample. We succeeded in representing all individual characteristics in the sample. Considering the cells in the table, 1 group of women was not interviewed, however, namely lower-educated women not having children.

Selected women were first approached by their general practitioner or the doctor's receptionist by telephone, and if willing to cooperate to an interview, they were contacted by one of the researchers (J.E.), also by telephone. Fifteen women were approached of whom 11 were willing to cooperate and were interviewed. Because no new themes emerged in the interviews, we then stopped participant recruitment. Reasons for not being willing to participate were lack of time $(n=3)$ and family circumstances $(n=1)$.

\section{Interviews}

Semistructured interviews were conducted in the women's own homes, following a checklist of topics (table 2). Ten participants were interviewed alone. One participant was interviewed in the presence of her partner. Remarks from the partner were not included in the analyses. The topic list was constructed on the basis of concepts of the Health Belief model, results from an earlier study we did on women's preferences regarding PCC, and characteristics of the approach that was used in the 'Parents to be' project. Topics included the invitational approach, information and prevention related to pregnancy, history of earlier pregnancies, perceived risks, social environment and prevention in general.

The interviews were conducted by the first 2 authors (E.H., psychologist and experienced interviewer or J.E., PhD student and trained interviewer) and lasted approximately $1 \mathrm{~h}$. All interviews were recorded and transcribed.

Analysis

The interviews were analyzed by the first 2 authors. The transcripts were read repeatedly and divided into segments which were then coded. Care was taken to ensure that the codes reflect-
Table 1. Participants with interview number, grouped according to gravidity, age and education level

\begin{tabular}{llllll}
\hline & \multicolumn{2}{l}{ Gravidity $=1$} & & \multicolumn{2}{l}{ Gravidity $>1$} \\
\cline { 5 - 6 } & $20-30$ years $>30$ years & & $20-30$ years $>30$ years \\
\hline Basic & 3 & & 10,11 & 7 \\
Intermediate & 3 & & 9 & $1,2,5$ \\
College/University & 6 & 8 & & 4 \\
\hline
\end{tabular}

Education levels according to the classification of Statistics Netherlands (http://www.cbs.nl).

Table 2. Topic list for interviews

\begin{tabular}{ll}
\hline Major topic & Questions about \\
\hline Invitational & - invitational letter \\
approach & - timing of the PCC invitation \\
& - relation with general practitioner \\
& - suitable person(s) to give PCC \\
\hline Information & - knowledge about pregnancy \\
and preven- & - knowledge about preventive behaviors \\
tion related & - perceived influence of the mother on the \\
to pregnancy & baby's health \\
& - sources of information about pregnancy \\
\hline History & - appropriate moment for PCC \\
\hline Perceived risks & - perceived risk that baby would not be healthy \\
& - use of prenatal diagnostics \\
\hline Social & - opinion and influence of partner \\
environment & - opinion and influence of important others \\
\hline Prevention & - perceived influence on own health \\
in general & - reported behavioral change \\
& - sources of information \\
& - attitude towards health promotion \\
\hline &
\end{tabular}

ed the total content of a segment and accurately captured the respondent's meanings. The codes in each interview were then compared to those in each other interview to create broader categories that linked codes across interviews. Also, tree diagrams were made that reflected different levels of codes with regard to each other. On the basis of the categories and the tree diagrams, key themes were defined $[11,12]$.

The work of coding and subsequent analysis was divided between E.H. and J.E., and the results of each step in the analysis were discussed before moving to the next step. We used Kwalitan [13], a qualitative research software package, to electronically code and manage data. 


\section{Results}

With regard to the approach that was used in the project 'Parents to be', 10 participants recognized the invitational letter when we showed it and 5 considered a letter the most appropriate way to be invited for PCC. Six participants considered the general practitioner the most suitable person to give PCC, 2 preferred a midwife and 1 preferred a gynecologist, because of his specialized knowledge. With regard to the most suitable moment for PCC, 4 participants indicated that preconception information is useful, because 'you can better be well informed about certain subjects before you get pregnant'. Another 4 participants indicated that they would prefer counseling during the first trimester of pregnancy, for example 'between the pregnancy test and the first visit to the midwife ... some moment in that period would be right for me. For myself, I think that is soon enough, because, well, it can just as well take another year before you get pregnant' (interview 2). Two participants indicated that advice before conception is useful, but they associated PCC with advice about things one can do to enlarge the chance to get pregnant, and not with preventive behavior.

\section{Key Themes That Emerged from the Data}

The motives the participants mentioned for not responding to the PCC invitation had to do with 3 main themes: perceived sufficient knowledge, perceived lack of risk and misunderstanding the aim of PCC. These themes combined to influence the decision not to respond, although 1 theme could usually be defined as the most prominent.

\section{Perceived Sufficient Knowledge}

Seven participants mentioned that they did not need PCC because they had enough knowledge already. Some also mentioned that they did not expect to gain any new knowledge from PCC. This concerned both women who had been pregnant and women who had not been pregnant before they received the invitation. For example: 'I knew a lot already because I have a lot of experience with pregnancies in my environment' (interview 1), 'I think I would have gone (if PCC had been a regular service), but only before the first (pregnancy), not with the third ... I don't think that you need more information with the second or third' (interview 5) and 'I had an idea about what was going to be told, and I thought, well, that's not new for me' (interview 6).
At the same time, a perceived lack of knowledge was an important reason for the participants to consider PCC useful for other people. Examples included: 'I think it is fine for women who are pregnant for the first time, because they are not very well informed' (interview 5), 'I can imagine that it's useful if you have specific questions' (interview 6) and 'I think it's good for very young women' (interview 9).

\section{Perceived Lack of Risk}

Seven participants mentioned that they had already lived fairly healthy before they got pregnant. Ten participants reported that they changed certain behaviors during pregnancy. Most notably, taking folic acid, eating healthy food, refraining from certain foods, not smoking, not cleaning the cat's box and taking more rest. When asked how big they thought their risk of a child with a congenital malformation was, all indicated they thought they only had a small risk. For example: 'I hardly thought about it, it didn't really apply to me, it doesn't run in the family and I was 25 with the boys and 28 with her ... of course, you sometimes think "what if ...?", but I've never thought of taking a test' (interview 10). Ten participants had no prenatal diagnostic tests, because 'there was no reason'. Taken together, these statements reflect the perception of these participants that they only had a small risk of congenital malformations in their unborn child, due to a perceived absence of risk factors and a perceived healthy lifestyle.

Paralleling the findings concerning perceived knowledge, perceived risk factors and unhealthy behavior were mentioned as reasons for the usefulness of PCC for other people. For example: 'My sister in law for instance, she is married with her cousin, so there is a greater chance that the baby won't be healthy' (interview 3 ) and 'I can imagine a target group ... for instance people that you sometimes see in the shopping centre, smoking a cigarette while pushing a baby pram' (interview 6).

\section{Misunderstanding the Aim of PCC}

Four participants associated PCC with getting pregnant. These women mentioned that they would only have visited the general practitioner if getting pregnant took longer then they had expected. For example: 'I think you only go if it just doesn't work, I mean, it's something between the two of you, but when you've tried for a couple of months and then you think, maybe we should visit a doctor' (interview 9).

Women who have problems getting pregnant were seen as a target group for PCC by these participants. For 
example: 'Women like my friend. She has been trying for a long time now and then you clutch at each straw, all information is welcome then' (interview 10).

\section{Discussion}

This study gives valuable insights into women's motives for not participating in PCC. It is important to recognize that all participants were concerned about maintaining their health and about the health of their unborn baby, and that the majority reported that they had changed behaviors during pregnancy in favor of the health of their unborn child. All but one of the women subscribed to the value of preventive behaviors and a healthy lifestyle. Nevertheless, the women did not consider PCC useful for themselves, and this view was mainly based on 3 themes: perceived sufficient knowledge, perceived lack of risk and misinterpretation of the aim of PCC.

Perceived sufficient knowledge appeared to be an important motive influencing response. Although we do not know what the actual knowledge level of participants prior to pregnancy was, different knowledge assessments about pregnancy-related risk factors and preventive measures among women of childbearing age have shown that they lack knowledge about essential, general items like folic acid use [14-16]. Besides, in the 'Parents to be' project the highest knowledge level was found among women who were pregnant or had recently been pregnant [16]. This suggests that women overestimate their knowledge level prior to pregnancy, and that it is being pregnant that boosts knowledge acquisition about health risks in pregnancy.

A perceived lack of risk due to a perceived healthy lifestyle and the absence of congenital malformations or diseases in the family also was an important motive influencing response. This finding corresponds to the results of some recent studies about participation in screening programs, which showed that feeling healthy and a perceived lack of risk were reasons for not taking part $[17,18]$. The results of our study suggest that perceived risk not only influences decisions about persons' own health, but also decisions that may have consequences for the health of women's unborn babies. This is supported by results from Aalfs et al. [19], who found that women seeking reproductive genetic counseling for a familial genetic risk factor during pregnancy estimated their chance of having an affected child as lower and took the initiative for referral less often themselves, than women seeking reproductive genetic counseling before conception. Women's esti- mation of genetic risk may not be in accordance with the actual risk figures, however. In our study, complications such as gestational diabetes or preterm birth were not seen by all participants as complications, for instance. Research by Charron-Prochownik et al. [20] showed that adolescents with diabetes were not aware of the risks of pregnancy-related complications with diabetes, and consequently felt that severe complications would not happen to them. Holing et al. [21] found that fewer than half of their population-based sample of women with diabetes planned their pregnancies, and results from Janz et al. [22] showed that only about one third of women with established diabetes seek preconception care.

The third influence on response was misunderstanding the aim of PCC. Almost half of the participants associated PCC with advice about (in)fertility. This suggests that for these women the aim of PCC was not made clear enough in the invitational letter. On the other hand, statistics from a Dutch Internet site on preconception information have shown that the majority of visitors was interested in information about how to get pregnant, and only in a second instance was looking for information about health risks [23]. This indicates that information about fertility and about how to get pregnant is important for the target group and may be essential to reach that group.

Our sample size, as is typical of qualitative research, was small, and the results cannot be generalized to the wider population in a statistical sense. The women we interviewed were broadly representative of the total group of women who did not respond to the PCC invitation and got pregnant within 1 year after the invitation, with the exception of lower-educated women who got pregnant for the first time. This suggests that the results may apply more widely, although this remains to be tested. We did not find any pattern of results that was related to age, education or gravidity, but the number of participants in this study was too small to draw conclusions from this, so this also remains to be tested.

In future research, additional data should be collected about the views of particular subgroups of women that were insufficiently represented in this study, that is lower-educated women contemplating pregnancy for the first time, women from ethnic minorities and women belonging to high-risk groups (such as congenital malformations in the family or suffering from a chronic disease, for which taking part in PCC is of even greater importance than for other couples). Currently, we are conducting a focus group study with immigrant women to gain more insight into their perceptions of and their needs 
concerning PCC. Furthermore, it would be interesting to look at the motives of couples who do take part in PCC. Insight into their motives could give additional starting points for the implementation of PCC.

\section{Conclusion}

This study highlights the importance of recognizing women's understandings and perceptions and taking them into consideration when planning future implementation of PCC. The results suggest that a more tailored approach may be necessary for certain (groups of) women, addressing the reasons why women do not consider themselves part of the target group for PCC.

Furthermore, including information in PCC about fertility and about how to get pregnant might be an instrument to heighten the response. Another way to achieve this may be to focus on personalized information in the invitation and not on general information that women can easily gain via other sources.

The idea of PCC is that timely given information about risk factors and potential harmful habits renders couples contemplating pregnancy the opportunity to change habits, due to which adverse pregnancy outcomes can be prevented. It can be concluded from the results that the view that counseling, and adjusting potential harmful habits, should take place already before conception was not selfevident for some participants. This suggests that it is essential to create a social basis for this view to enable that PCC evolves to standard care.

\section{Acknowledgements}

We thank all general practitioners and their patients for their participation in this study. The Netherlands Organization for Health Research and Development (ZonMw) provided funding for this study.

\section{References}

$\checkmark 1$ Baird PA, Anderson TW, Newcombe HB, Lowry RB: Genetic disorders in children and young adults: a population study. Am J Hum Genet 1988;42:677-693.

2 Dutch Council for Public Health and Health Care (RVZ): Advice on prevention of congenital anomalies (in Dutch). Zoetermeer, May 1990.

3 Czeizel AE: Ten years of experience in periconceptional care. Eur J Obstet Gynecol Reprod Biol 1999;84:43-49.

4 Ray JG, O'Brien TE, Chan WS: Preconception care and the risk of congenital anomalies in the offspring of women with diabetes mellitus: a meta-analysis. QJM 2001;94:435444.

5 de Weerd S, Thomas CM, Cikot RJ, SteegersTheunissen RP, de Boo TM, Steegers EA: Preconception counseling improves folate status of women planning pregnancy. Obstet Gynecol 2002;99:45-50.

6 ACOG technical bulletin. Preconceptional care. Number 205 - May 1995. American College of Obstetricians and Gynecologists. Int J Gynaecol Obstet 1995;50:201-207.

$\checkmark 7$ Moos MK: Preconceptional health promotion: a health education opportunity for all women. Women Health 1989;15:55-68.

8 Wildschut HI, Van Vliet-Lachotzki EH, Boon BM, Lie Fong S, Landkroon AP, Steegers EA: Preconception care: an essential part of the care for mother and child (in Dutch). Ned Tijdschr Geneeskd 2006;150:1326-1330.
9 Cefalo RC, Moos MK: Preconceptional Health Promotion: A Practical Guide, 2nd edition. St. Louis, Mosby-Yearbook, 1995.

10 Elsinga J, Van der Pal-de Bruin KM, Le Cessie S, De Jong-Potjer LC, VerlooveVanhorick SP, Assendelft WJJ: Preconception counselling initiated by general practitioners in the Netherlands: reaching couples contemplating pregnancy. BMC Fam Pract 2006; 7:41.

11 Miles MB, Huberman AM: Qualitative Data Analysis: An Expended Sourcebook. Thousand Oaks, Sage Publications, 1994.

12 Wester F, Peters V: Qualitative Analysis: Basic Principles and Procedures (in Dutch). Bussum, Coutinho, 2004.

13 Peters VAM: User Manual Kwalitan 5.0 (in Dutch). Nijmegen, Katholieke Universiteit Nijmegen, 2000.

14 Pastuszak A, Bhatia D, Okotore B, Koren G: Preconception counseling and women's compliance with folic acid supplementation. Can Fam Physician 1999;45:2053-2057.

15 Sayers GM, Hughes N, Scallan E, Johnson Z: A survey of knowledge and use of folic acid among women of child-bearing age in Dublin. J Public Health Med 1997;19:328-332.

16 de Jong-Potjer LC, Elsinga J, Le Sessie S, PalDe Bruin KM, Schoorl E, Sneeuw KCA, Verloove-Vanhorick SP, Assendelft WJJ: Knowledge of pregnancy-related risk factors amongst women of childbearing age: a population based study. BMC Family Practice, submitted 2007.
17 Madlensky L, Esplen MJ, Goel V: Reasons given by relatives of colorectal cancer patients for not undergoing screening. Prev Med 2004;39:643-648.

18 Weinberg DS, Turner BJ, Wang H, Myers RE, Miller S: A survey of women regarding factors affecting colorectal cancer screening compliance. Prev Med 2004;38:669-675.

19 Aalfs CM, Mollema ED, Oort FJ, De Haes JC, Leschot NJ, Smets EM: Genetic counseling for familial conditions during pregnancy: an analysis of patient characteristics. Clin $\mathrm{Ge}-$ net 2006;66:112-121.

20 Charron-Prochownik D, Sereika SM, Wang SL, Hannan MF, Fischl AR, Steward SH, Dean-McElhinny T: Reproductive health and preconception counseling awareness in adolescents with diabetes: what they don't know can hurt them. Diabetes Educ 2006;32: 235-242.

21 Holing EV, Shaw Beyer C, Brown ZA, Connell FA: Why don't women with diabetes plan their pregnancies? Diabetes Care 1998; 21:889-895.

-22 Janz NK, Herman WH, Becker MP, Charron-Prochownik D, Shayna VL, Lesnick TG, Jacober SJ, Fachnie JD, Kruger DF, Sanfield JA, et al: Diabetes and pregnancy. Factors associated with seeking pre-conception care. Diabetes Care 1995;18:157-165.

23 Preconception Information on ZwangerStraks.nl (in Dutch). Erfocentrum. Erfo mailnieuws, No. 32, 28 April 2005. 